\title{
Social and environmental indexes to determine the impacts of closed neighbourhoods in Brazil
}

\author{
F. J. M. Pedrazzi \& F. T. Conceição \\ UNESP, Univer. Estadual Paulista, IGCE, Brazil
}

\begin{abstract}
São Paulo State, in Brazil, is getting increasingly crowded, like in other third world countries around the world, so should give great importance to city development. This work considered the phenomenon of closed neighbourhoods (CN) as an important factor to city planning, papers report many impacts of this model of neighbourhoods in other countries, but in Brazil its impacts are not yet well listed in the literature. The aim of this work was to determine indicators to achieve the social and environmental performances and verify their applicability on three different closed neighbourhoods in São Paulo state, Brazil. The indicators were condensed on indexes: water management, waste management, energy and emissions, legal compliance, environment and buildings, risk management, health and education and governance. The preliminary results indicated several social and environmental problems in all indexes.

Keywords: gated villages, closed neighbourhoods, social and environmental performance, indicators and indexes, Brazil.
\end{abstract}

\section{Introduction}

Against the past urbanization trend, where downtowns were considered the best living place, a new trend for the dispersion of the outlying neighbourhoods is being verified in a fractal model [1]. In this model, appear several enclaves in the outliers of the cities, many of them with access control, edges with wall or fences and closed gates, restricting the access [2].

Checking this situation, Manzi and Smith-Bowers [3] set out by arguing that a taxonomy of gating and walls in residential areas is better expressed through the term gated residential development (GRD), rather than the more confusing 'gated community' or 'closed neighbourhood'. 
The same authors say that GRD are places where the public spaces were privatized, like greenbelts and recreational areas, this become a problem if the government does not prepare the city for growth, since entrepreneurs are taking advantage of new spatial scale thinking, besides understanding the local government failures.

It's known that in countries as Europe and North America the concept of "club goods" is the most frequent cause of walling, like the concept of exclusivity. This means the exclusivity of living in a closed neighbourhood with all the privileges are a preponderant factor for the family to choose living in it. In others, like Brazil, Argentina and other third world countries, the main walling causes are the absence of public security and the lack of efficient public services.

Despite all the reasons, closed neighbourhoods may cause several environmental and social impacts. Bockstaller and Girardin [4] proposed the validation of the use of indicators to conduct environmental analysis, since these tools have become prerequisites for the implementation of the concept of sustainable development [5]. These indicators, when tangible stimulate the interest and participation of people [6,7], discussion of improving the socioenvironmental issues at the community level falls.

The decision criteria for the definition of the indicators must follow the principles from Donnelly et al. [8], which produced a hall of "strategic indicators of environmental performance”. Thus, the aim of this work was to determine 8 indexes, composed with at least 5 indicators each, to assess the social and environmental impacts of closed neighbourhoods.

\section{Description of method}

The environmental and social performance index is based on a Brazilian standard NBR ISO 14031:2004, Social Carbon methodology [9, 10] and from Donnelly et al. [8]. These methodologies are based on application of environmental and social indicators to achieve better management practices.

The application of the indicators was based on the PDCA, an iterative fourstep management method used in business for the control and continuous improvement of processes and products (Figure 1). The first stage, "PLAN", consisted in determining the indicators. They are based on the literature, visits to closed neighbourhoods. It was considered also the scientific bibliography, manuals, standards and empirical experiences. Based on these data, where created indicators to represent the management practices. Table 1 presents the scores to each indicator, being the worse and better management practices scored with 1 and 5 points, respectively.

The next step was "DO". All the developers must give permission for this study in the closed neighbourhoods. Application of the proposed method will be conducted using semi-conducted interviews and visits to the manager or the president of the closed neighbourhoods. The questionnaire asked respondents to rate suggested responses on a scale from 1 to 5, allowing respondents to add their own responses. 


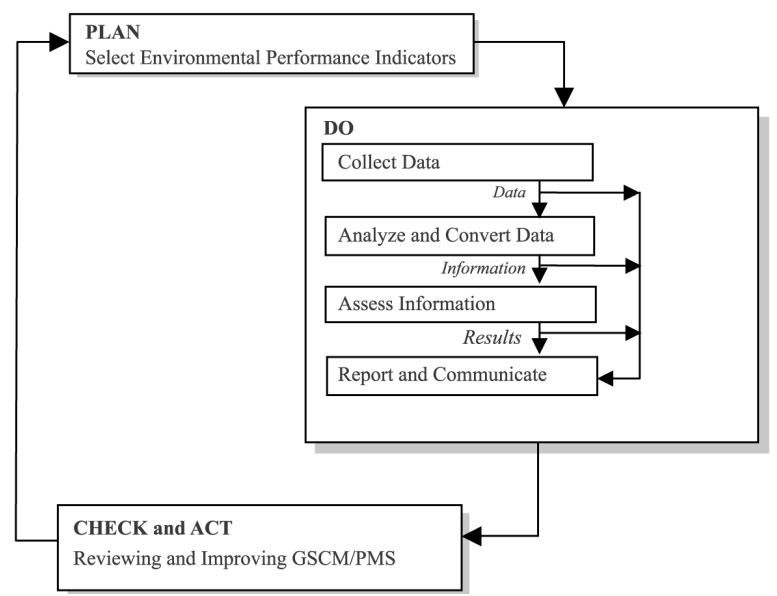

Figure 1: $\quad$ Plan - Do - Check - Act, modified from NBR ISO 14031:2004.

Table 1: $\quad$ Possible scores to each indicator.

\begin{tabular}{cccccc}
\hline $\begin{array}{c}\text { Scenario / } \\
\text { score }\end{array}$ & $\mathbf{1}$ & $\mathbf{2}$ & $\mathbf{3}$ & $\mathbf{4}$ & $\mathbf{5}$ \\
\hline Rating & Bad & Critical & Regular & Satisfactory & Good \\
\hline
\end{tabular}

The third and fourth steps ("CHECK” and “ACT”) consist about the analysis of the indicators. The social and environmental performance is composed by the arithmetic mean of the indexes. Each index is composed by the arithmetic mean of the indicators, being the score below 3 (regular) considered as a bad result.

After this, it will be suggested an action plan, based on OECD model (pressure-state-response) [11], which allowed identifying the social and environmental impacts, assisting to the management strategies.

\section{Indexes and indicators}

The proposed indicators were chosen inside 9 indexes with at least 5 indicators each. The indexes chosen were: water management, waste management, energy and emissions, legal compliance, environment and buildings, risk management, health and education and governance.

\section{Water management:}

- Water resources management plan;

- $\quad$ Type and compliance for subterranean water catchment;

- $\quad$ Targets for water consumption and its reduction in common areas;

- $\quad$ Campaigns for responsible water use;

- Water leaks detection and loss index; 
- Sectorization of water consumption;

- Water reuse/recycling;

- Monitoring of superficial and groundwater potability;

- Wastewater discharge;

- Storm water management program.

Waste management:

- $\quad$ Solid waste management plan;

- $\quad$ Frequency and selective collection;

- Waste reduction targets;

- Emissions control in waste collecting;

- Management of construction and demolition waste;

- $\quad$ Management of green waste;

- Intermediate disposal of undifferentiated waste;

- Destination for fluorescent bulbs;

- $\quad$ Batteries and lead-acid batteries scrap management;

- Used tires management and disposal;

- $\quad$ Plaster waste management and disposal.

Energy and emissions:

- $\quad$ Power consumption management plan;

- $\quad$ Lighting of common sites;

- $\quad$ Street lighting technologies;

- $\quad$ Sources of energy for common areas;

- Purchases of efficient appliances and electronics;

- Monitoring electricity usage;

- Emissions management plan;

- Monitoring of greenhouse gases emissions and their reductions;

- Internal transport and logistics.

Legal compliances:

- $\quad$ Plan for recovery of degraded areas;

- Mandatory preservation areas;

- Environmental infractions;

- Extension of green areas in the neighbourhood;

- $\quad$ Permeable batch in the neighbourhood;

- $\quad$ Existence and management practices for contaminated areas;

- $\quad$ Compliance with licensing requirements;

- $\quad$ Licence to management of paint cans, solvents, fuel oil and lubricating oil;

- $\quad$ Granting water use.

Soil use and biodiversity:

- $\quad$ Public roads pavement; 
- Quotient between impervious areas (ai) and built area (ac);

- Exposed soil and erosions;

- Vegetable coverage of open areas;

- Stability margins and slopes;

- Common green area per capita;

- Maintenance of green areas methods;

- Urban forestry in sidewalks;

- Environmental enrichment with native species;

- Exotic pets in public areas;

- Diversity forestry and vegetation management;

- Vegetation cover per inhabitant;

- Permeable areas perpetuation of gardening in homes

Risk management:

- $\quad$ Fire fighting system and people training brigade;

- Analysis of social risks;

- Analysis of environmental risks;

- Program risk management;

- Training of staff in emergency situations;

- Security guards qualification.

Environment and buildings:

- Buildings rules standardization;

- Grease trap installation;

- Standardization of sidewalks;

- Control of soil impermeabilization in homes;

- Rainwater use politics;

- Solar heating politics;

- Waste management and control in buildings;

- Supervision of buildings and housing;

- Legal and certified wood use - collective and/or residual buildings;

- Supplier control.

Health and education:

- Program of environmental education;

- Community kitchen- gardens;

- Education program for transit for children and youth;

- Monitoring with aged;

- Program for prevention and control of chronic no communicable diseases;

- Education program for finance and policy for children and youth;

- Nutritional education program; 


\section{Governance:}

- Quality management program;

- $\quad$ Community relationship;

- Community representation in collegiate;

- $\quad$ Opened accountancy;

- $\quad$ Sustainable buying policies.

\section{Case study}

To validate the proposed method, 3 closed neighbourhoods in Sorocaba/SP, Brazil were chosen, as listed above:

\section{Closed neighbourhood A (CN A):}

Opened in 2006, a medium class, total area of $113,163,04 \mathrm{~m}^{2}$, green reserved area of $17,692.82 \mathrm{~m}^{2}(16 \%)$, pavimentation for streets of $28,721.12 \mathrm{~m}^{2}(25 \%)$, area reserved for public goods of 5,871.41 $\mathrm{m}^{2}(5 \%)$, lots of $60,687.32 \mathrm{~m}^{2}(54 \%)$, number of lots 212, average area for each lot $=250 \mathrm{~m}^{2}$;

Closed neighbourhood B (CN B):

Opened in 1973, high class, 100 lots, total area of $922.471,82 \mathrm{~m}^{2}$, green reserved area of $0,00(0 \%)$, pavimentation for streets of $129,959.00 \mathrm{~m}^{2}(14 \%)$, area reserved for public goods of $164.616,71 \mathrm{~m}^{2}(18 \%)$, lots of $617.400,00 \mathrm{~m}^{2}(67 \%)$, number of lots of 100 , average area for each lot $=5,000 \mathrm{~m}^{2}$;

\section{Closed neighbourhood $C(C N C)$ :}

Opened in 2010, medium class, total area of 363,000.00 $\mathrm{m}^{2}$, green reserved area of $90,919.46 \mathrm{~m}^{2}(25 \%)$, pavimentation for streets of 91,401.21 (25\%), area reserved for public goods of $17.678,21 \mathrm{~m}^{2}$ (5\%), lots of 146,707.21 $\mathrm{m}^{2}(40 \%)$, recreation area of $16,293.19(4 \%)$, number of lots of 414 , average area for each lot $=312 \mathrm{~m}^{2}$;

Sorocaba is a Brazilian city located in São Paulo State. It is the fourth most populous in the interior of São Paulo with a population of 594,000 inhabitants. It has an area of $456.0 \mathrm{~km}^{2}$, of which $349 \mathrm{~km}^{2}$ (76\%) area is urban. The region of Sorocaba possesses fourteen municipalities, with more than 1.3 million inhabitants.

In 2010, the population density of Sorocaba was $1,113.92$ inhabitants $/ \mathrm{km}^{2}$, while the average region is 148 inhabitants $/ \mathrm{km}^{2}$. Sorocaba has a potential annual per capita consumption estimated at USD 1,000 for the urban population and USD, being the $30^{\text {th }}$ Brazilian city with the greatest potential for consumption [12].

It is estimated that in Sorocaba over 100,000 people lives in closed neighbourhoods and dwellings, which are spread by chaotically in the peripheral areas of city. The gated communities are predominantly formed by houses of middle and high classes, with terrain ranging from 250, 300, 700 and 5,000 $\mathrm{m}^{2}$. As increases the size of the lots, there is an empirical relationship with the purchasing power of the owners. 

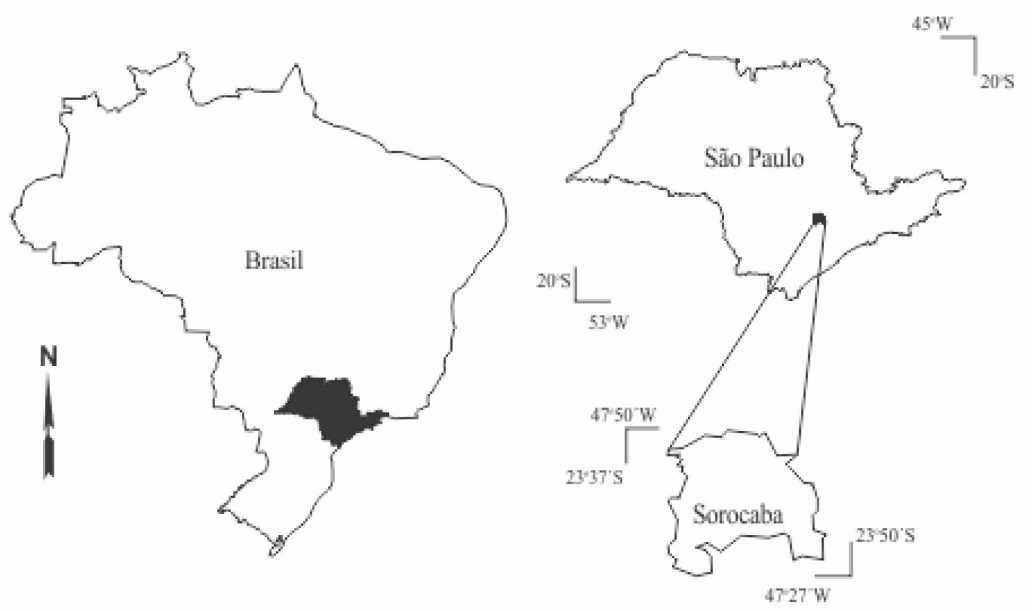

Figure 2: $\quad$ Location of Sorocaba, SP, Brazil.

Over the last twelve years, the city has undergone several urbanization projects, becoming today one of the top ten best cities or living in São Paulo State. Despite its credits, there is a lot of pressure from commercial developers to create high density and high rise buildings. In many cases, the "sustainable" small scale ideas clash with the business plans of big developers.

Sorocaba won over 3 years state awards from a program called "Green-blue municipality”, which aims to environmental management of São Paulo State. Sorocaba has a municipal office to care about environmental programs since 2009. Some modest attitudes are being done; the municipality has seventy miles of bike paths created in the city's main avenues.

\section{Preliminary results}

The method proposed is being applied in these 3 closed neighbourhoods at Sorocaba. Figure 3 presents some picture illustrating the problems found in these closed neighbourhoods. Preliminary results indicated several social and environmental negative aspects, such as:

Water management: process of siltation caused by the lack of indigenous forests vegetation cover in the areas of permanent preservation and urban drainage without desanding (CN B, Figure 3A);

Waste management: lack of selective waste collection policy causes loss of recyclable materials and unnecessary disposal on landfills or waste dumps (CN A, Figure 3B); 

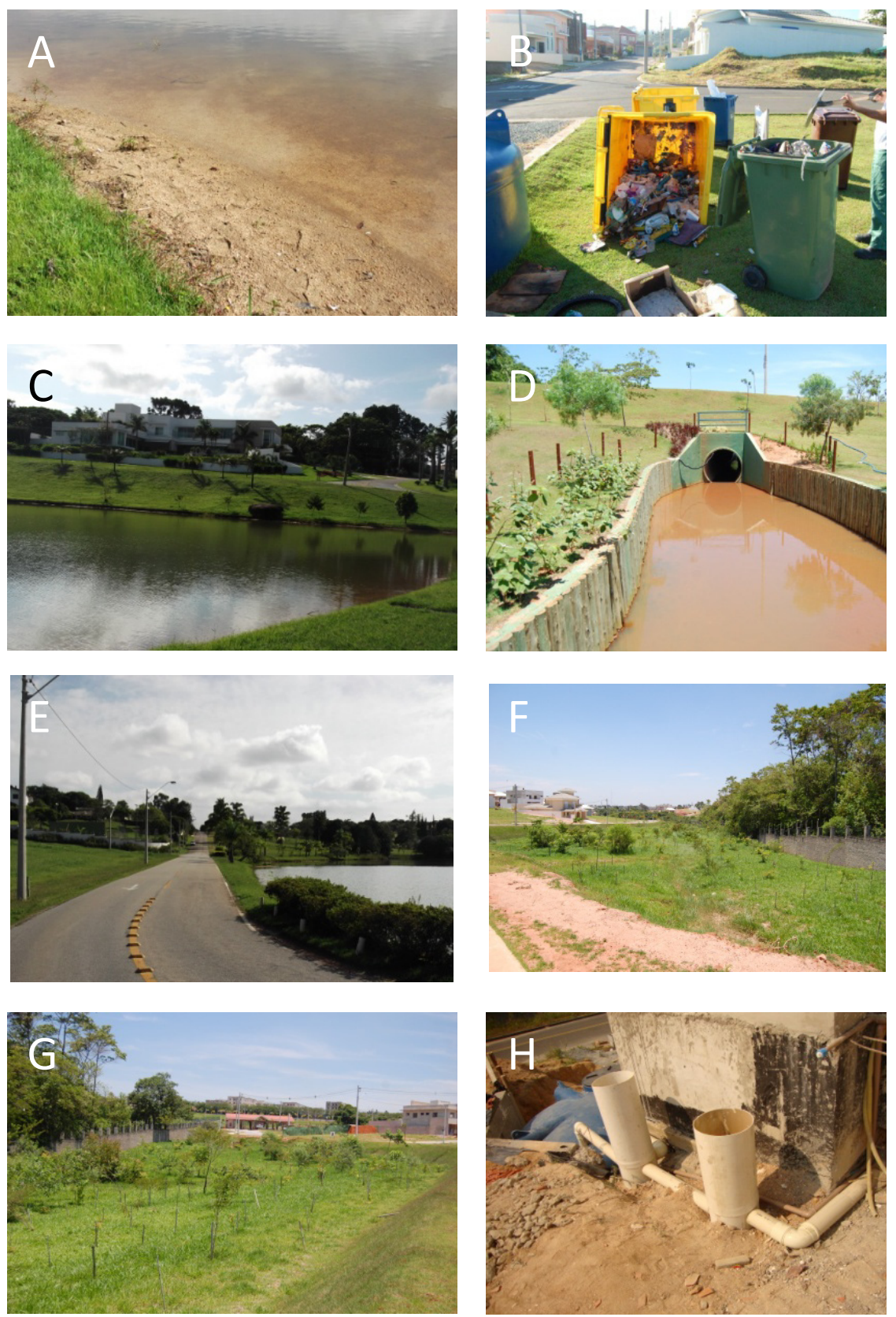

Figure 3: $\quad$ Some environmental problems, verified on a field survey. 
Energy and emissions: lack of control over the use of electricity leads to loss of energy and generation of hazardous waste (lamps, batteries, among others).

Legal compliances: areas of permanent preservation, protected by Brazilian law without indigenous forests coverage (CN B, Figure 3C). Lack of environmental compliance (granting for water use) for river channel modification and margins occupied by non-indigenous species (CN A, Figure 3D); Areas of permanent preservation, protected by Brazilian law (30 m on each margin) occupied by urban use (CN B, Figure 3E).

Soil use and biodiversity: Soil exposure without any management practices (CN C, Figure 3F). Reforestation project without any observation of introduction of species threatened by extinction, according to IUCN (CN A, Figure 3G).

Risk management: there is no survey of social and environmental risks in the 3 closed neighbourhoods studied;

Environment and buildings: Despite the lack of policies for sustainable buildings, some individual actions can be observed, i.e. rainwater collection to reuse in toilets and irrigation in a private house (CN A, Figure $3 \mathrm{H}$ ).

Health and education: no education practices and health-related activities are applied in the 3 closed neighbourhoods studied;

Governance: quality management program, community relationship, community representation in collegiate, opened accountancy and sustainable buying policies are not documented.

\section{Conclusion}

The method proposed, using index and indicators, is feasible for an appraisal of the social and environmental management of closed neighbourhood.

At the moment, the preliminary results obtained in 3 closed neighbourhoods at Sorocaba city, located in São Paulo State, indicated various social and environmental problems in all indexes.

At the end of this work, the numerical scores of each index will be achieved, with these results it is going to be possible to list and make action plans to the each problems occurring in these closed neighbourhoods, allowing proposing improvements in social and environmental management practices for their sustainability.

\section{Acknowledgements}

We would like to thank João de Araújo Junior for reviewing the manuscript and for the National Council of Scientific and Technological Development (CNPq) for the financial support. 


\section{References}

[1] Caldeira, T. Cidade de Muros. Crime, segregação e cidadania em São Paulo. São Paulo: Edusp/Editora 34.

[2] Atkinson, R. The politics of gating (A response to Private Security and Public Space by Manzi and Smith-Bowers), European Journal of Spatial Development, Debate Article. Available on: http://www.nordregio.se /Global/EJSD/Debate/debate080506.pdf. 2008.

[3] Manzi, T. and Smith-Bowers, B. Private Security and Public Space: New Approaches to the Theory and Practice of Gated Communities. European Journal of Spatial Development. Debate article. Available on www.nordregio.se/EJSD/refereed22.pdf. 2006.

[4] Bockstaller C, Girardin P. How to validate environmental indicators. Agric Syst. Volume 76, PP-639-653. 2003.

[5] Hansen, J.W. Is agricultural sustainability a useful concept? Agricultural Systems 50, 117-143. 1996.

[6] Fung, A., Wright, E.O. (Eds.). Deepening democracy: institutional innovations in empowered participatory governance. Verso, London. 2003.

[7] Graymore, M.L.M, Sipe, N.G., Rickson, R.E. Sustaining Human Carrying Capacity: a tool for regional sustainability assessment. Ecological Economics, 69, PP. 459-468. 2010.

[8] Donnelly, A., Jones, M., O’Mahony, T., Byrne, G. Selecting environmental indicator for use in strategic environmental assessment. Env. Imp. Assessment review, vol. 27, PP-161-175. 2007.

[9] Rezende D. and Merlin S. Carbono social - Agregando valores ao desenvolvimento sustentável. Editora: PEIROPOLIS. Available on: http://www.socialcarbon.org/uploadDocs/Documents/Social_Carbon_book pt.pdf. 2003.

[10] Santos C.K.N. 2008. Metodologia do carbono social - manual do multiplicador. Palmas, Instituto Ecológica.

[11] OECD. OECD core set of indicators for environmental performance reviews. Environment monographs, number 83. Paris. 1993.

[12] IPC. Os 500 municípios que mais consomem no Brasil. Available on http://www.ipcbr.com/downpress/Ranking_IPC_2010_2009_500Maiores. pdf. Accessed on 14/02/2012. 2010. 